\title{
I solated intestinal manifestation of graft-versus-host disease following renal transplantation
}

\author{
Michael Praktiknjo ${ }^{1}$, Dominik Boes ${ }^{1}$, Michael Majores ${ }^{2}$, Christian P. Strassburg ${ }^{1}$, Rainer P. \\ Woitas $^{1}$
}

1. Department of Medicine I, University of Bonn, School of Medicine, Bonn, Germany. 2. Department of Pathology, University of Bonn, School of Medicine, Bonn, Germany.

Correspondence: Michael Praktiknjo. Address: Department of Medicine I, University of Bonn Sigmund-Freud-Strasse 25, 53127 Bonn, Germany. Email: michael.praktiknjo@ukb.uni-bonn.de

Received: April 21, 2014

DOI : $10.5430 /$ crim.v2n1p56
Accepted: May 4, $2014 \quad$ Online Published: November 2, 2014

URL: http://dx.doi.org/10.5430/crim.v2n1p56

\section{Abstract}

Graft-versus-host disease (GVHD) is a potentially lethal complication commonly occurring after hematopoietic stem cell transplantation and non-irradiated blood cell transfusion in patients with underlying immunodeficiency. In solid organ transplantation GVHD however is a rarity. There have been four cases of GVHD after renal transplantation, most of them with fulminant systemic clinical manifestation and mostly associated with blood transfusions. We report the first case of a four HLA-antigen mismatched kidney transplant patient who presented with diarrhea due to intestine-only manifestation of GVHD and was treated successfully with quadruple immunosuppression.

\section{Keywords}

Graft-versus-host disease, Kidney transplantation, Colitis, Diarrhea, Immunosuppression, Human leukocyte antigens

\section{Introduction}

Graft-versus-host disease is a potentially lethal complication occurring after transplantation, frequently observed following hematopoietic stem cell transplantation in up to $50 \%$ of cases ${ }^{[1]}$. However in solid organ transplantation GVHD is a less frequent phenomenon depending on the organ transplanted. Highest rates of occurrence after solid organ transplantation are observed after small bowel (5.6\%) and liver transplantation $(1 \%-2 \%)^{[2,3]}$. The diagnosis is made by clinical appearance of fever, skin rash, weight loss and diarrhea quickly leading to multisystem disease. Because of the high rate of fatal progression (up to $75 \%$ mortality) early diagnosis is crucial but often difficult due to the non-specific clinical features ${ }^{[4]}$. Clinical symptoms are often attributed to infectious complications or immunosuppressive medication.

Standardized treatment protocols for solid organ transplant patients are not yet established. There have only been four case reports on GVHD after kidney-only transplantation ${ }^{[5]}$. All of the cases exhibited multiple clinical symptoms. However, to date there is no report on a case with isolated intestinal manifestation of GVHD. 


\section{Case report}

We report of a 64-year-old Caucasian female with end-stage renal disease of unknown origin. She underwent ABO- and sex-compatible renal transplantation from a 50-year-old deceased donor. Cross-match showed a four HLA-antigens mismatch. Induction therapy was performed using basiliximab. Immunosuppression included tacrolimus (trough level 6-8ng/ml), 2000mg mycophenolate mofetile (MMF) and 5mg prednisone. Beginning on postoperative day (POD) 5 the patient had impaired graft function. Due to biopsy proven acute cellular rejection anti-thymoglobulin was administered for 8 days. At time of discharge (POD34) the patient had adequate diuresis and serum creatinine level was 1.7mg/dl. The patient received multiple red blood cell transfusions that had not been irradiated.

On POD 262 the patient was readmitted with low-grade fever, fatigue and chronic mucoid to watery diarrhea. Clinical examination showed anorexia (BMI 15.7) due to significant weight loss of $14.3 \%$ (40.3kg compared to $47 \mathrm{~kg}$ at $160 \mathrm{~cm}$ height). Supportive parenteral nutrition was started. Blood work showed elevated serum creatinine level at 3.7mg/dl and anemia (hemoglobin $8.2 \mathrm{mg} / \mathrm{dl}$ ). Leukocyte and platelet counts were $5.12 \mathrm{G} / \mathrm{l}$ and $350 \mathrm{G} / \mathrm{l}$ respectively. Further peripheral

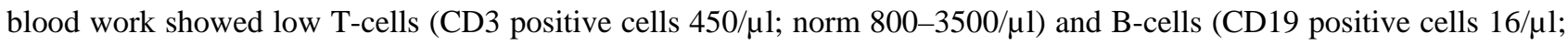

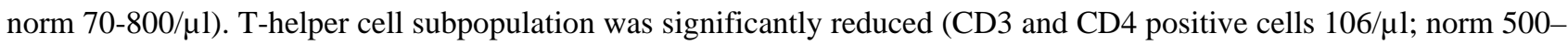

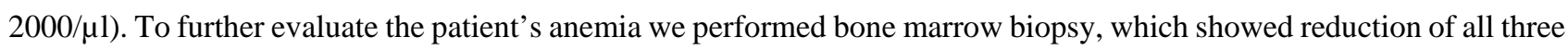
cell lines. We attributed this finding to toxic effects of immunosuppressive medication. Urine and blood parameters showed no further sign of infection. Repeated blood, urine and stool cultures could not isolate bacterial, fungal or viral pathogens. PCR from stool and blood samples for viral nucleic acid including norwalk-, adeno- and cytomegalovirus were repeatedly negative.

Despite the lack of signs of infection antibiotic therapy was started due to differential diagnoses including infectious gastroenteritis and MMF associated GI-toxicity. Initial MMF-dosage of 2000mg was reduced to $720 \mathrm{mg}$ mycophenolate per day. Despite this therapy the symptoms remained unchanged. We performed colonoscopy, which macroscopically showed moderate pancolitis with diffuse erythema, erosions and fibrinous adhesions (see Figure 1). Histopathological evaluation of the tissue samples showed extensive impairment of crypt architecture, partial crypt loss, mucosal denudation, increased numbers of apoptotic bodies and predominant lympho-plasmatic infiltration (see Figure 2).

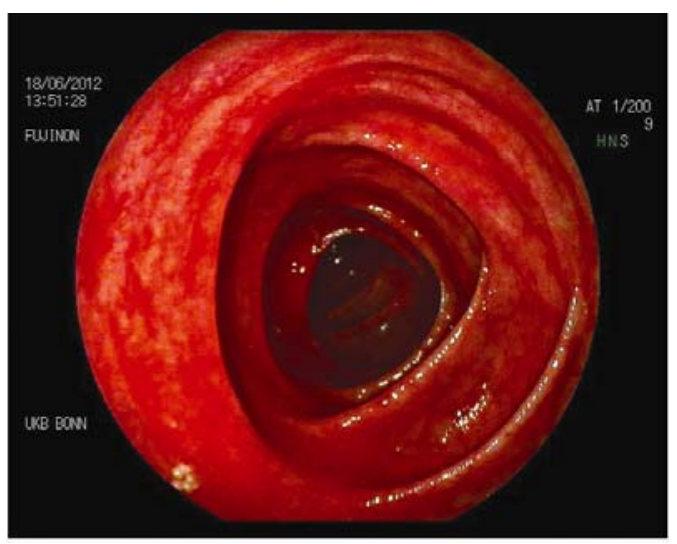

Figure 1. Macroscopic picture of the patient's colon shows diffuse erythema, erosions and fibrinous adhesions.

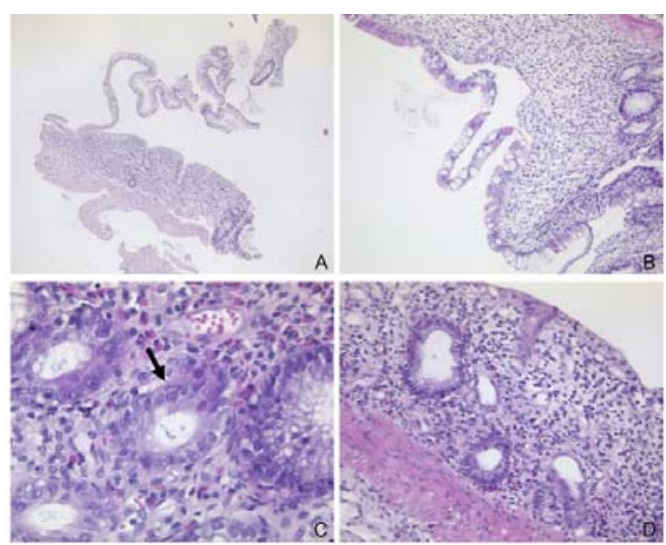

Figure 2. (HE-staining) Mildly flattened mucosa with detachment of large epithelial casts (A, B). Mildly stromal lymphoplasmacellular and partial eosinophilic infiltration. Apoptosis in crypt basis (arrow) (C). Ubiquitanous residual microcrypts (D).

After further review of the histopathologic specimens, the above-mentioned findings, according to the NIH reference pathology, were consistent with intestinal GVHD grade $3^{[6]}$. Chimerism could not be demonstrated directly. Meanwhile 
we performed direct antiglobulin test (DAT), which resulted positive. We attributed this observation as an indirect sign of graft-versus-host aggression. According to NIH consensus criteria the patient's disease was consistent with a single organ (intestine) moderate to severe manifestation of GVHD (severity score of 2-3) ${ }^{[7]}$.

After the diagnosis of graft-versus-host disease was established we started steroid pulse treatment with prednisolone 100 mg per day for 10 days, then tapered down in the course of 4 weeks. In addition we intensified the immunosuppressive regimen to a quadruple therapy with sirolimus (trough level 4-7 ng/ml), minimal-dose tacrolimus (trough level $<2 \mathrm{ng} / \mathrm{ml}$ ), increased MMF dosage (500 mg three times a day) and prednisone (5 mg per day).

Following this treatment the patient's diarrhea stopped and creatinine level decreased. Protocol colonoscopy 48 days after treatment showed no pathologic findings macro- and microscopically. The patient was discharged on POD 347.

\section{Discussion}

We discuss the first case of a female renal transplant patient with isolated intestinal manifestation of GVHD that was treated successfully ${ }^{[5]}$. In our case the clinical appearance of the patient is consistent with infectious colitis, MMF-GI-toxicity and an intestinal manifestation of overlap GVHD according to the 2005 NIH consensus criteria ${ }^{[7]}$. Our patient's chronic nausea, vomiting and diarrhea caused a wasting-like syndrome over 100 days after transplant. Further evidence to the diagnosis GVHD can be given by showing peripheral chimerism for example via fluorescence in-situ hybridization (FISH) analysis in cases of XY/XX-chromosome incompatible transplantation or peripheral HLA-typing by flow cytometry ${ }^{[5]}$. As mentioned above showing chimerism in peripheral blood samples via flow cytometry at the time was not available at our institution. Also neither anti-ABO-antibodies against the patient nor Y-chromosomes in bowel specimen were detectable due to sex- and ABO-compatible donor organ.

Like the majority of clinicians we first considered infectious colitis to be the most likely differential diagnosis at the time of admission. However, when symptoms persisted despite under antibiotic and antiviral therapy we virtually could rule out an infectious cause of the patient's impairments.

The histologic findings of the bowel specimen led us to the differential diagnosis of MMF-related GI-toxicity. MMF-toxicity is known to display GVHD-like histologic changes in the intestine ${ }^{[8]}$. However, the initial diagnosis of MMF-toxicity as a far more common cause than GVHD was abandoned upon the lack of clinical response to reduction of MMF-dosage and the uncommon severity (grade 3) of GVHD in our patient.

The only finding that was neither consistent with infectious colitis nor MMF related GI-toxicity was the positively reacting DAT. Retrospectively, GVHD was considered relatively late after ruling out common causes due to non-response to treatment.

Standard treatment protocols for GVHD after solid organ transplantation are not established. The majority of authors suggest immunosuppressive therapy referring to treatment protocols in bone marrow transplant patients, whereas others suggest pausing immunosuppression ${ }^{[9,10]}$. Kim et al. published a case of intestinal GVHD after 4/6 HLA mismatched deceased donor kidney transplantation. The authors decided to withdraw immunosuppression compromising MMF and tacrolimus and treat the patient with high dose steroids only. However, that patient developed progressive multiorgan failure and passed only 19 days after the diagnosis was established ${ }^{[11]}$.

Despite having a single organ manifestation only, we classified our patient as moderate to severe GVHD in accordance to NIH staging because of the significant weight loss and the need of nutritional supplement. Based on this staging we decided to intensify systemic immunosuppression to avoid fulminant severe GVHD with high mortality. 
Impaired immunocompetence of the recipient due to immunosuppressive medication is a well-documented risk factor. Immunocompromised recipients lack the ability to eliminate passenger donor leukocytes and therefore are more susceptible to develop GVHD ${ }^{[12,13]}$.

The mechanism of GVHD in solid organ transplantation is not fully understood. The suggested mechanisms include tissue injury leading to a release of proinflammatory, major histocompatibility complex (MHC) and costimulatory molecules. Furthermore proliferation and differentiation of donor T-cells and expression of MHC-class-II are involved. These processes require immunocompetent cells for costimulation of effector cells. It is well known that simple manipulation or ischemia-reperfusion of the bowel can cause severe inflammation. Due to the high immunogenicity the gut naturally seems to be one of the favored target organs that are affected by GVHD ${ }^{[14,15]}$. It is conceivable that a favorable condition for GVHD was present in our patient. The hypocellular bone marrow and the low numbers of immunocompetent peripheral blood cells might have contributed to a scenario where donor leukocytes were able to translocate into the bowel to cause the patient's symptoms.

The immunosuppressive regimen of the patient may be a putative risk factor as well. Although the combination of a calcineurin inhibitor (CNI) and MMF is commonly considered safe recent studies and meta analyses describe a higher incidence of (severe) GVHD in patients under tacrolimus and MMF-based immunosuppression ${ }^{[16-18]}$. Our patient was on tacrolimus, MMF and steroids. MMF inhibits leukocyte proliferation by inhibiting inosine 5'-monophosphate dehydrogenase, which is a rate-limiting enzyme in the de novo synthesis of guanosine. Recent studies have shown differential effects of MMF on T-cell subpopulations. The addition of MMF to the immunosuppressive regimen preserves regulatory T-cell (T-reg) subpopulation. T-reg cells are known to prevent and reduce GVHD. However, the response of different T-reg cells (activated or resting, donor or host derived) to MMF might differ and is not well understood ${ }^{[19]}$. The above mentioned immune dysregulations caused by MMF might have impaired the host's functional T-cell response (more than the donor's). This may have favored the survival and proliferation of donor derived immunocompetent cells thus, leading to the development of the patient's GVHD. As mentioned above we treated our patient with intensified quadruple immunosuppression. The CNI-based regimen was altered to the mTOR-inhibitor sirolimus with only low dose CNI. According to the reported case we rather suggest an intensified quadruple immusuppression with steroid pulse instead of withdrawal of immunosuppressive medication.

In other organs GVHD appears within first few weeks to months post transplant ${ }^{[4]}$. The reported cases of GVHD after kidney transplantation show a later time frame (mean 142.4, median 145, range 17 to 262 days after transplant). In our case GVHD occurred 262 days after transplant. It is conceivable, that the treatment of acute cellular rejection with anti-thymoglobulin (ATG) depleted not only the host's but also the donor T-lymphocytes. Thus delaying the onset of GVHD significantly. ATG is known to reduce the risk of GVHD. Especially in hemato-oncologic regimens it is used to prevent GVHD after allogeneic stem cell transplantation ${ }^{[20,21]}$. Another possible explanation for the late onset of GVHD in kidney transplant patients could be the amount of transplanted immunocompetent donor cells. Donor lymphocytes are present roughly for two weeks in liver transplant patients. The amount of transplanted immunologic donor cells in liver transplants is approximately $10^{9}$ to $10^{10}$, which is comparable to the amount of donor cells transplanted in stem cell transplantation and considerably lower than in small bowel graft. In kidneys there is clear evidence that resident leukocytes are present and further T-cells being recruited in traumatic situations like ischemia-reperfusion (i.e. during transplantation). The amount of transferred immunologic cells by human kidney grafts is unclear but considered to be significantly lower compared to liver or intestinal grafts ${ }^{[22,23]}$. We suggest a correlation between the amount of donor T-cells and the occurrence of GVHD. Low numbers of host-specific donor cells are less likely to be activated by their corresponding epitope and therefore might lead to the observed longer period after transplantation before the onset of clinical symptoms.

In conclusion, even though in our patient peripheral chimerism could not be demonstrated, the patient's clinical appearance with wasting-like syndrome and good clinical response to escalated quadruple immunosuppression and the 
lack of evidence for other causes as well as the patient's immunodeficiency, as a suggested favorable condition, strongly suggest an intestinal graft-versus-host-reaction. We recommend that in kidney transplant patients presenting with chronic diarrhea without signs of infection or viral disease, especially with impaired immune status, GVHD should be included early into the differential diagnosis even up to 8 months after transplantation. Intensified immunosuppressive treatment should be considered even though an impaired immune competence might have led to the disease.

\section{References}

[1] Jacobsohn DA, Vogelsang GB. Acute graft versus host disease. Orphanet J Rare Dis. 2007 Sep 4; 2: 3. PMid:17784964 http://dx.doi.org/10.1186/1750-1172-2-35

[2] Mazariegos GV, Abu-Elmagd K, Jaffe R, et al. Graft versus host disease in intestinal transplantation. Am J Transplant. 2004 Sep; 4(9): 1459-65. PMid:15307833 http://dx.doi.org/10.1111/j.1600-6143.2004.00524.x

[3] Taylor AL, Gibbs P, Bradley JA. Acute graft versus host disease following liver transplantation: the enemy within. Am J Transplant. 2004 Apr; 4(4): 466-74. PMid:15023138 http://dx.doi.org/10.1111/j.1600-6143.2004.00406.x

[4] Assi MA, Pulido JS, Peters SG, et al. Graft-vs.-host disease in lung and other solid organ transplant recipients. Clin Transplant. 2007 Jan-Feb; 21(1): 1-6. PMid:17302584 http://dx.doi.org/10.1111/j.1399-0012.2006.00573.x

[5] Kato T, Yazawa K, Madono K, et al. Acute graft-versus-host-disease in kidney transplantation: case report and review of literature. Transplant Proc. 2009 Nov; 41(9): 3949-52. PMid:19917421 http://dx.doi.org/10.1016/j.transproceed.2009.05.030

[6] Shulman HM, Kleiner D, Lee SJ, et al. Histopathologic diagnosis of chronic graft-versus-host disease: National Institutes of Health Consensus Development Project on Criteria for Clinical Trials in Chronic Graft-versus-Host Disease: II. Pathology Working Group Report. Biol Blood Marrow Transplant. 2006 Jan; 12(1): 31-47. PMid:16399567 http://dx.doi.org/10.1016/j.bbmt.2005.10.023

[7] Filipovich AH, Weisdorf D, Pavletic S, et al. National Institutes of Health consensus development project on criteria for clinical trials in chronic graft-versus-host disease: I. Diagnosis and staging working group report. Biol Blood Marrow Transplant. 2005 Dec; 11(12): 945-56. PMid:16338616 http://dx.doi.org/10.1016/j.bbmt.2005.09.004

[8] Parfitt JR, Jayakumar S, Driman DK. Mycophenolate mofetil-related gastrointestinal mucosal injury: variable injury patterns, including graft-versus-host disease-like changes. Am J Surg Pathol. 2008 Sep; 32(9): 1367-72. PMid:18763324 http://dx.doi.org/10.1097/PAS.0b013e31816bf3fe

[9] Chinnakotla S, Smith DM, Domiati-Saad R, et al. Acute graft-versus-host disease after liver transplantation: role of withdrawal of immunosuppression in therapeutic management. Liver Transpl. 2007 Jan; 13(1): 157-61. PMid:17192857 http://dx.doi.org/10.1002/lt.20982

[10] Martin PJ, Rizzo JD, Wingard JR, et al. First- and second-line systemic treatment of acute graftversus-host disease: recommendations of the American Society of Blood and Marrow Transplantation. Biol Blood Marrow Transplant. 2012 Aug; 18(8): 1150-63. PMid:22510384 http://dx.doi.org/10.1016/j.bbmt.2012.04.005

[11] Kim JM, Kim SJ, Joh JW, et al. Graft-versus-host disease after kidney transplantation. J Korean Surg Soc. 2011 Jun; 80 Suppl 1: S36-9. http://dx.doi.org/10.4174/jkss.2011.80.Suppl1.S36

[12] Adeva Andany M, Martínez W, Arnal F, et al. Transfusion-associated graft-versus-host disease in a renal transplant recipient. Nephrol Dial Transplant. 1994; 9(2): 196-8. PMid:8190340

[13] Ferrara JL, Levine JE, Reddy P, et al. Graft-versus-host disease. Lancet. 2009 May 2; 373(9674): $1550-61$. http://dx.doi.org/10.1016/S0140-6736(09)60237-3

[14] Engel DR, Koscielny A, Wehner S, et al. T helper type 1 memory cells disseminate postoperative ileus over the entire intestinal tract. Nat Med. 2010 Dec; 16(12): 1407-13. PMid:21113155 http://dx.doi.org/10.1038/nm.2255

[15] Washington K, Jagasia M. Pathology of graft-versus-host disease in the gastrointestinal tract. Hum Pathol. 2009 Jul; 40 (7): 909-17. PMid:19524102 http://dx.doi.org/10.1016/j.humpath.2009.04.001

[16] Sabry W, Le Blanc R, Labbé AC, et al. Graft-versus-host disease prophylaxis with tacrolimus and mycophenolate mofetil in HLA-matched nonmyeloablative transplant recipients is associated with very low incidence of GVHD and nonrelapse mortality. Biol Blood Marrow Transplant. 2009 Aug; 15(8): 919-29. PMid:19589481 http://dx.doi.org/10.1016/j.bbmt.2009.04.004

[17] Ram R, Yeshurun M, Vidal L, et al. Mycophenolate mofetil vs. methotrexate for the prevention of graft-versus-host-disease--systematic review and meta-analysis. Leuk Res. 2014 Mar; 38(3): 352-60. PMid:24418750 http://dx.doi.org/10.1016/j.leukres.2013.12.012 
[18] Al-Kadhimi Z, Gul Z, Chen W, et al. High Incidence of Severe Acute Graft-Versus-Host Disease with Tacrolimus and Mycophenolate Mofetil in a Large Cohort of Related and Unrelated Allogeneic Transplantation Patients. Biol Blood Marrow Transplant. 2014 Apr 4. pii: S1083-8791(14)00165-7.

[19] Derniame S, Lee F, Domogala A, et al. Unique effects of mycophenolate mofetil on cord blood T cells: implications for GVHD prophylaxis. Transplantation. 2014 Apr 27; 97(8): 870-8. PMid:24670298 http://dx.doi.org/10.1097/01.TP.0000438203.19595.3f

[20] Crocchiolo R, Esterni B, Castagna L, et al. Two days of antithymocyte globulin are associated with a reduced incidence of acute and chronic graft-versus-host disease in reduced-intensity conditioning transplantation for hematologic diseases. Cancer. $2013 \mathrm{Mar}$ 1; 119(5): 986-92. PMid:23096591 http://dx.doi.org/10.1002/cncr.27858

[21] Veltri L, Regier M, Cumpston A, et al. Incidence and Pattern of Graft-versus-Host Disease in Patients Undergoing Allogeneic Transplantation after Nonmyeloablative Conditioning with Total Lymphoid Irradiation and Antithymocyte Globulin. Bone Marrow Res. 2013; 2013: 414959. PMid:23691325 http://dx.doi.org/10.1155/2013/414959

[22] Ysebaert DK, De Greef KE, De Beuf A, et al. T cells as mediators in renal ischemia/reperfusion injury. Kidney Int. 2004 Aug; 66(2): 491-6. PMid:15253695 http://dx.doi.org/10.1111/j.1523-1755.2004.761_4.x

[23] Vielhauer V, Anders HJ, Pérez de Lema G, et al. Phenotyping renal leukocyte subsets by four-color flow cytometry: characterization of chemokine receptor expression. Nephron Exp Nephrol. 2003; 93(2): e63. PMid:12629274 http://dx.doi.org/10.1159/000068517 